\title{
Interaction and cognitive engagement: An analysis of four asynchronous online discussions
}

\author{
ERPING ZHU \\ Center for Research on Learning and Teaching, University of Michigan, 1071 Paslmer \\ Commons Building, 100 Washtenaw Ave, Ann Arbor, MI 48105, USA \\ (E-mail: ezhu@umich.edu)
}

Received: 6 July 2005; accepted: 11 March 2006

\begin{abstract}
Online discussion plays a unique role in face-to-face and distance teaching and learning. Interaction and student cognitive engagement during the online discussion are critical for constructing new understanding and knowledge. This article analyzes types of interaction that occur during online discussions, examines levels of student cognitive engagement in each discussion, and explores their effects on and implications for learning and teaching in higher education. By combining methods of social network analysis with qualitative content analysis, the article explores new methodologies for analyzing participation, interaction, and learning that take place online, and suggests areas for research in learning and teaching online.
\end{abstract}

Keywords: asynchronous discussion, cognitive engagement, computer-mediated communication, discussion forum, electronic conferencing, interaction, teaching and learning online

Advances in technology have enhanced communications between students and the instructor, and among students themselves. Many college instructors, due to easy access to communication technology tools, have moved or extended part of a classroom discussion to an online forum, where students and the instructor continue their discussion on course-related topics. Instructors sometimes find it difficult to facilitate class discussions online because there remains scant knowledge about interaction and student cognitive engagement in the asynchronous online discussion. This article analyzes types of interaction in four asynchronous online discussions, examines student cognitive engagement in each discussion, explores factors that may cause differences in interaction and cognitive engagement, and highlights possible implications for learning and teaching online and for research in computer-mediated communication (CMC). 


\section{Theoretical context}

\section{Research in $C M C$}

Over the past decades, CMC has emerged as a research area in education, communication, psychology, sociology, linguistics, and technology. Early research in CMC has focused on aspects of participation. Research revealed that for students who are shy to participate and collaborate in a classroom setting might change their participation behavior online. Instead of remaining silent, they may be very active and engaged online, as there is no time restriction or interruption for their online participation in class activities (Harasim, 1990). Similar to managing face-to-face discussions, the online instructor takes the responsibility of keeping discussions on track, contributing knowledge and insights, weaving together various discussion threads and course components, and maintaining group harmony (Rohfeld \& Hiemstra, 1995). In addition, online instructors must choreograph online discussions differently from those conducted in a face-to-face mode (Heckman \& Annabi, 2004).

Interaction is another area of research in CMC that explores differences of online and face-to-face interaction (Gunawardena et al., 1997; Heckman \& Annabi, 2004) and examines patterns and quality of online interaction (Fahy et al., 2001; Zhang \& Carr-Chellman, 2001). Research in online interaction is often framed within the theoretical context of sociocultural and collaborative learning theories. For instance, studies revealed that interaction and group work could impact varied student learning outcomes (Berge \& Collins, 1995; Jonassen et al., 1995). Furthermore, researchers (Garrison et al., 2001; Hara et al., 2000; Henri, 1992; Zhu, 1998), using different models and techniques, analyzed social, cognitive and meta-cognitive aspects of learning in CMC. For example, using patterns of knowledge construction, Zhu (1998) illustrated how new insights, knowledge, perspectives, and understandings result from instructional scaffolding within students' zone of proximal development (Vygostsky, 1978). Garrison et al. (2001) proposed a four-phase model (trigger, exploration, integration, and resolution) to explore and examine the nature and quality of critical inquiry in computer conferencing. Their study found that student responses were highest in the exploration phase and lowest in the resolution phase. Using Transcript Analysis Tool (TAT), Fahy et al. (2001) analyzed the interactional and structural exchange patterns that occurred in the online discussion. Studies found that 
information-related statements are likely to comprise the largest portion of online discussion (Fahy et al., 2001; Gunawardena et al., 1997). Despite a vast amount of research in participation, interaction, critical thinking, and social and cognitive aspects of learning in $\mathrm{CMC}$, there are many questions and mysteries that remain to be explored and answered. For instance, what is the relationship between interaction pattern and student cognitive engagement in an online discussion? How can CMC be conducive for online learning and teaching, especially in higher education?

Sociologists Bob Kling and Barry Wellman suggested that when CMC networks link people, institutions, and knowledge, they are computer-supported social networks (Wellman \& Hiltz, 2004), which can be studied to reveal relationship and interaction among members. Education researchers Fahy et al. (2001) employed theories of social network together with their TAT model to study exchange patterns observed in discussion transcripts. They found that exchange patterns in an online conference could be assessed by analysis of a combination of structure and content evidence. In addition to structural analysis of online interaction, Jeong (2005) suggested that online interaction be examined from social, semantic, temporal, symbolic, and physical dimensions. The multi-dimension analysis can reveal complex relations among messages' content, timing, ownership, and the critical discourse a discussion session generates.

\section{Research framework}

Interaction, as suggested by educational research, is one of the most important components of teaching and learning experiences (Moore, 1993; Vygotsky, 1978). Thus, instruction is effective when it is in the form of a dialogue where learners can interact with peers or mentors who challenge and scaffold their learning. As sociological researchers suggest, instruction ideally occurs in an environment where learners use socially mediated and intellectual tools to achieve cognitive development (Rogoff, 1990).

Electronic conferencing serves as a sociocultural tool that students can use to interact with one another, exchange ideas, discuss issues, and collaborate to solve problems. Through electronic discussions, students and instructors can voice their opinions, analyze peers' comments, and reflect on their learning, thereby increasing interpsychological and intrapsychological activities to promote an individual's cognitive growth and development. 
As suggested by sociologists, computer networks are social networks (Wellman, 2001). A social network here is defined as those individuals with whom a person is in some sort of regular and sustained contact (Fahy et al., 2001; Ridley \& Avery, 1979). Information exchange and interaction among learners during the discussion help form a specialized social network, which holds together a group of learners for the purpose of achieving specific learning goals. The network contains and is sustained by exchange of information and by interaction among members. In this social network, learners assume various roles while interacting with one another.

I agree that the interaction in an online discussion offers us a "gold mine of information concerning the psycho-social dynamics" among participants (Henri, 1992, p. 118) because student participation in and contribution to an online discussion are conscious activities that entail learning. Furthermore, online discussion messages are artifacts of learning that demonstrate student behaviors during the learning process.

While most studies in CMC examine themes and semantics, interaction, and participation by way of content analysis, few attempt to use structure and content approach (Fahy et al., 2001). I believe that a combination of structural and content analysis of CMC transcripts offers a richer understanding of social and cognitive aspects of learning occurred in online discussions. Thus, social network and content analysis are actual methodologies used to examine learners' interaction and cognitive engagement in this study. The network properties such as size, centrality, and density are employed to explain the interaction among group members and the structure of interpersonal communication in the network.

For the purpose of this study, interaction, defined as "mutual and reciprocal action" in Merriam-Webster's Collegiate Dictionary (1997), is operationalized as mutual and reciprocal responses in the online discussion. Cognitive engagement in a face-to-face learning environment is observable when learners are giving sustained attention to a task requiring mental effort (Corno \& Mandinach, 1983). Although we cannot observe cognitive engagement in an online learning environment, it is discernible from discussion messages. For example, attention to specific information, analysis and synthesis of information, and distinction between information are visible in discussion transcripts. Cognitive engagement in this study is therefore clarified as attention to related readings and effort in analyzing and synthesizing readings demonstrated in discussion messages. Cognitive 
engagement, as defined, involves seeking, interpreting, analyzing, and summarizing information; critiquing and reasoning through various opinions and arguments; and making decisions. Extended engagement in cognitive activities, especially activities that require higher order-thinking skills, is believed to produce useful learning (Stoney \& Oliver, 1999).

It is understood that an individual's ability to reason builds upon the ability to recognize and discriminate certain facts and principles. Reasoning obviously requires more cognitive effort than simple recognition (Gagne, 1985; Piaget, 1970). How much and what students learn largely depend on each individual's effort to understand content materials. Of course, individual levels of cognitive engagement may be influenced by the instructor's encouragement and discussion facilitation as well as by intrinsic motivation (Corno \& Mandinach, 1983). Different levels of cognitive engagement in the online discussion may contribute to varied individual learning and knowledge acquisition.

\section{Research questions}

Several questions are raised to examine types of interaction and levels of student cognitive engagement during the online discussion:

- What types of interaction occurred in four asynchronous online discussions?

- What levels of student cognitive engagement were found in these asynchronous online discussions?

- Is there any relationship between types of interaction and levels of cognitive engagement in these asynchronous online discussions?

- What effect and implication may types of interaction and cognitive engagement have for online teaching, learning, and research?

\section{Study participants}

The study participants were 71 students from 3 different colleges in a small public university. They included undergraduates from the College of Education and the College of Health Professions, and graduate students from the College of Professional Studies and the College of Education. The percentage of female students in four courses averaged $80 \%$, with a high $90 \%$ in the undergraduate education course, $85 \%$ in the graduate education course, $83 \%$ in the undergraduate health 
professions course, and $63 \%$ in the professional studies course. All students were required to participate in the instructor-assigned asynchronous online discussions in a regular semester (12-14 weeks) and received varied grades for their participation. A few students, however, instead of contributing to the discussion, remained silent during discussion sessions. All students were offered a technology orientation session before the first day of class. However, the orientation, which focused on the email system, the online discussion tool, and the course web site, was recommended for the undergraduate students, but mandatory for the students in both distance learning graduate courses. Instructors played different roles in the four online discussions, such as observer, manager, and participant (see Table 1).

\section{Data collection and analysis}

At the end of the semester, I selected and downloaded two discussion transcripts from each of the four classes for analyses without any reference to discussion topics and messages. I avoided using discussion transcripts from the first or last week of discussion, because the beginning or ending messages tend to focus more on technology, logistics, and discussion management, which is less representative of a normal class discussion that focuses on course content.

Content analysis, as a research technique for the objective, systematic, quantitative description of the manifest content of communication (Berelson, 1952, p. 519), is adopted to analyze and determine student cognitive engagement in the online discussion. Content analysis, involving reading each discussion message, was conducted using the Analytical Framework for Cognitive Engagement in Discussion (see Table 2), a scheme that incorporates the coding system "Note Categories and Interaction Types" (Zhu, 1998, p. 238), the theoretical framework of content analysis (Henri, 1992), and Bloom's cognitive domains of learning (1956). Great effort was made to avoid the subjectivity in assigning levels of cognitive engagement to discussion messages and to reach objectivity in content analysis for this study.

In the analysis, a student assistant and I read each discussion message three times. We first read messages and separately assigned a level of cognitive engagement to each message using the framework and then compared notes and reached agreement on levels of cognitive engagement for all messages. Twenty (about 8\%) out of 244 messages had to be discussed and reassigned levels of cognitive 


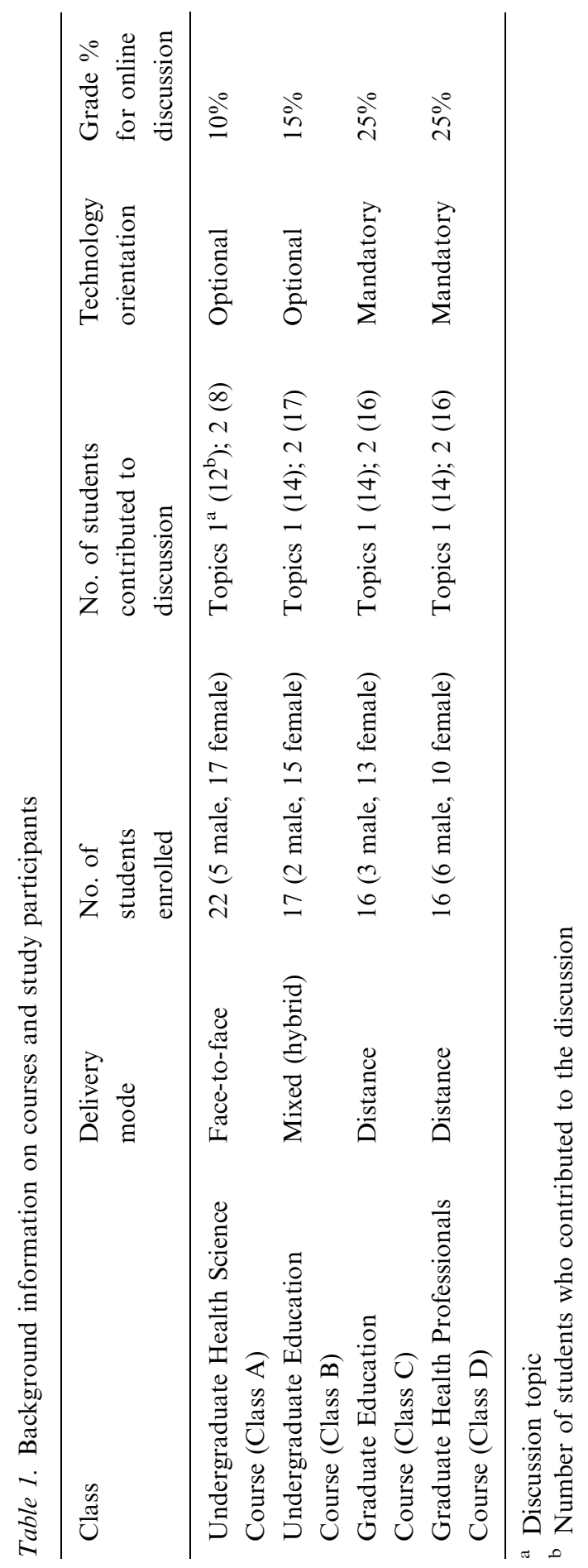




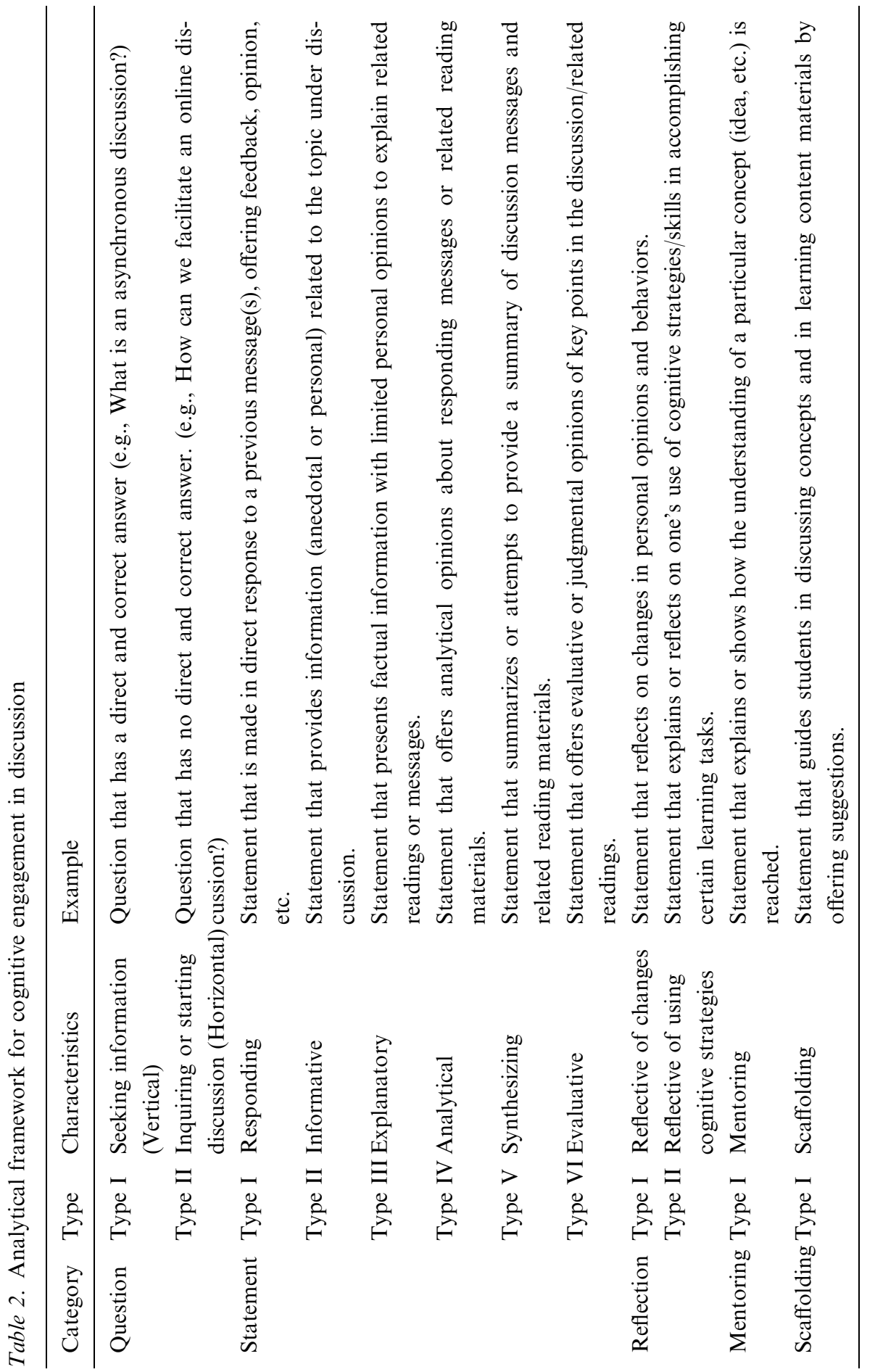


engagement. To ensure objectivity in content analysis, I planned to review the cognitive level assignment 6 months away from the initial assignment. Because the leave of the student assistant and my other commitment, the review did not start 12 months later; then I re-read all the messages and re-assigned levels of cognitive engagement without referring to the previous work. At that time, I re-adjusted the levels of cognitive engagement to four messages $(1.2 \%)$.

Using the analytical framework for cognitive engagement in discussion (see Table 2), I categorized questions as Type I (vertical), which aim at seeking information, and Type II (horizontal), which attempt to initiate a conversation. Statements were classified into 6 different types according to Bloom's learning hierarchy (1956). Statements ranged from the responding to the evaluative. Responding statements were made in direct responses to previous messages, offering factual information, feedback, and sometimes opinions. A statement that provided information (anecdotal or personal) related to the general discussion topic was defined as informative. A statement that presented factual information with limited personal opinions to explain related readings was clarified as explanatory. Analytical statements demonstrated thoughtful analysis. A statement that summarized or attempted to provide a summary of discussion messages and related readings was categorized as a synthesizing statement. Evaluative statements are those that offer evaluative or judgmental opinions of discussion points, topics, and related readings. Messages reflecting on one's learning or use of strategies during learning are named as Reflection Type I and Reflection Type II, respectively. Mentoring messages are those that connect readings and responses in an attempt to demonstrate processes or steps involved in understanding concepts and issues. Scaffolding messages support student learning and discussion by offering suggestion and guidance.

In analyzing types of interaction, I went beyond the direction of interaction (vertical and horizontal) as defined in my previous coding scheme (Zhu, 1998). In a discussion setting, group members sometimes will reply on or look for more capable members' answers or opinions rather than contributing to a topic discussion. This type of interaction is typically called vertical interaction. By contrast, in the horizontal interaction, members' desires to express their own ideas and opinions tend to be much strong because exchanges among the members bring in multiple perspectives, enrich the discussion, and become basis for understanding discussion topics and issues. In this study, interaction among students in all four online discussions was 
primarily horizontal. Therefore, the direction of interaction seems to offer insufficient information for distinguishing roles played by each student and the instructor, and for explaining the nature of interaction in online discussions.

Considering the online discussion as a computer-supported social network, I examined online interaction through the lens of network properties such as network size, centrality, and density. In this study, network members were students who participated in the online discussion. Size, referring to the number of network members, has direct impact on interaction. When a network is small, the potential personto-person interaction will be smaller. The size of a network and the interaction grow proportionally (Fahy et al., 2001; Ridley \& Avery, 1979; Rytina, 1982). Centrality, referring to the connection of one (point) member in the network with other (points) members, can be measured by the number of points to which a particular point is adjacent. Centrality in the online discussion is viewed as the connection or interaction of one member with others. Density describes the general level of linkage among points in a social network. The density of a network is defined as the number of lines in a network divided by the maximum number of all possible lines (Scott, 2000). Thus, the density a network is maximal, when all the points are connected. The density value of a network varies between 0 and 1 .

\section{One undergraduate course in health science}

This face-to-face course with 22 students ( 5 male and 17 female) had two Internet class discussions. The Internet sessions scheduled for Weeks 3 and 8 (in a 15-week semester) discussed course assignments. For both discussion sessions, each student was required to select and discuss a topic online. Student participation in the online class discussion accounted for $10 \%$ of the final course grade. For the purpose of the study, this course is referred to as Class A.

The first Internet discussion lasted for about two weeks and generated 24 discussion topics with a total of 271 messages. Two discussion topics, "El Nino" and "Social Impact of Land Mines" were selected for analysis. Twelve students participated in the "El Nino" discussion and 8 students joined in the discussion on "Social Impact of Land Mines." Other students did not contribute to the selected discussions. The average message was approximately 3.5 lines (roughly 87-99 words) for both discussions (see Table 3). The instructor read all students' messages, but did not participate in the discussion. The 
Table 3. Overview of two discussions in Class A

\begin{tabular}{llll}
\hline Topic & $\begin{array}{l}\text { Network Density } \\
\text { size }\end{array}$ & $\begin{array}{l}\text { Instructor's } \\
\text { message }\end{array}$ & $\begin{array}{l}\text { Average } \\
\text { message } \\
\text { line length }\end{array}$ \\
\hline $\begin{array}{l}\text { El Nino } \\
\text { (1st discussion) }\end{array}$ & 12 & $\begin{array}{l}20 \%[2 \times 13 / 12 \times(12-1)] \\
13 \text { messages total }\end{array}$ & $\begin{array}{l}3.25 \\
\text { (with } 27 \text { words/line) } \\
(87 \text { words) }\end{array}$ \\
$\begin{array}{l}\text { Social Impact } \\
\text { of Land Mines } \\
\text { (2nd discussion) }\end{array}$ & $\begin{array}{l}29 \%[2 \times 8 / 8 \times(8-1)] \\
8 \text { messages total }\end{array}$ & $0 \%$ & 3.7 lines \\
& & & $(99$ words) \\
\hline
\end{tabular}

network density is approximately 0.2 for the first discussion and 0.29 for the second.

The online discussion in the undergraduate health science course had no instructor involvement and participation, but enjoyed a great amount of information exchange among students.

\section{One undergraduate course in education}

This undergraduate education course enrolled 17 students ( 2 male and 15 female) and was taught in two instructional modes: face-to-face and online. Students met seven times on campus and spent the remaining class time completing online learning activities. The online discussion accounted for $15 \%$ of the final grade. Two discussions from Weeks 2 and 10 were among those selected for analysis. Students responded weekly to the instructor's questions and peers' responses as well. Fourteen students contributed to the discussion on "Cognition" and 17 students participated in the discussion on "Children's Cognitive Growth." The average message for the "Cognition" discussion was approximately 1.72 lines (about 46 words) and 5.1 lines (about 137 words) for the week 10 discussion. The instructor contributed $7 \%$ of the total messages in Week 2 and $8 \%$ in Week 10 (see Table 4). The network density is 0.25 in discussions for both weeks. This course is referred to as Class B later in the study.

The online discussion in the undergraduate education course enjoyed limited instructor participation and exchange among students. With an average of 46 words per message in the discussion on "Cognition," students posted definitions of cognition without interpretation and explanation. The messages from the discussion on "Children's 
Table 4. Overview of two discussions in Class B

\begin{tabular}{lllll}
\hline Topic & $\begin{array}{l}\text { Network } \\
\text { size }\end{array}$ & Density & $\begin{array}{l}\text { Instructor's } \\
\text { message }\end{array}$ & $\begin{array}{l}\text { Average message } \\
\text { line length }\end{array}$ \\
\hline $\begin{array}{l}\text { Cognition } \\
\text { (Week 2) }\end{array}$ & 15 & $\begin{array}{l}25 \%[2 \times 26 / 15 \times \\
(15-1)]\end{array}$ & $\begin{array}{l}7 \%(2 \\
\text { messages })\end{array}$ & $\begin{array}{l}1.72 \\
\text { (with 27 words/line) } \\
\text { (46 words) }\end{array}$ \\
$\begin{array}{l}\text { Children's } \\
\text { cognitive }\end{array}$ & 18 & $\begin{array}{l}25 \% \text { messages total) } \\
(18-1)]\end{array}$ & $8 \%(38 / 18 \times$ & 5.1 lines \\
growth \\
\begin{tabular}{l} 
(Week 10) \\
\hline
\end{tabular}
\end{tabular}

Cognitive Growth" became longer when students started bringing their own examples to explain children's cognitive growth.

\section{One graduate course in education}

The graduate education course with 16 students (3 male and 13 female) was considered a distance learning course by the university. Students met at the beginning of the semester for a mandatory technology and course orientation. The mid-semester face-to-face meeting featured guest speakers. During the final week, the class met again for student presentations. The instructor assigned weekly reflective questions for students to respond and discuss online. In addition, each student was asked to lead one week's discussion during the semester. Students' responsibilities in leading a discussion included starting the discussion, inviting peers to post reflections in a timely manner, and summarizing discussion messages. Student performance in the online discussion accounted for $25 \%$ of the final course grade. Transcripts of discussions from Weeks 2 and 10 were selected for analysis. Fourteen students participated in the first discussion "Language and Content Instruction" and 16 students joined in the second week discussion on "Teaching Methods and Techniques." The average message length for both weeks was about 12 lines (over 300 words). The instructor contributed nearly half of the messages for both weeks. The density is about 0.28 for both discussions (see Table 5). This class is referred to as Class $\mathrm{C}$ later in the study.

Unlike discussions from the previous classes, this online discussion enjoyed extensive instructor participation and interaction with 
Table 5. Overview of two discussions in Class $\mathrm{C}$

\begin{tabular}{lllll}
\hline Topic & $\begin{array}{l}\text { Network } \\
\text { size }\end{array}$ & Density & $\begin{array}{l}\text { Instructor's } \\
\text { message }\end{array}$ & $\begin{array}{l}\text { Average } \\
\text { message } \\
\text { line length }\end{array}$ \\
\hline $\begin{array}{l}\text { Language and } \\
\text { content instruction }\end{array}$ & 15 & $28 \%[2 \times 29 / 15 \times$ & $45 \%(13$ & 12.3 \\
(Week 2) & $(15-1)]$ & messages $)$ & (with 27 words/line) \\
Teaching methods & 17 & 29 messages total & $(332$ words) \\
and techniques & $28 \%[2 \times 38 / 17 \times$ & $45 \%(17$ & 13.42 \\
(Week 10) & $(17-1)]$ & messages) & $(362$ words) \\
\hline
\end{tabular}

students. In comparison, interaction among students themselves was less visible.

\section{One graduate course in professional studies}

This distance-learning graduate course enrolled 16 students (6 male and 10 female). In the first week of the semester, the class had one mandatory on-campus course and technology orientation. The instructor monitored class discussions online and taught the course using a course management system. Students were instructed to respond to four questions and commented on at least two peers' responses each week. Student performance in the online discussion accounted for $25 \%$ of the final course grade. Fourteen students participated in the discussion on "Pro-Life" and "Pro-Choice" and 16 students joined in the discussion on "AIDS Disease." The instructor's messages accounted for $29 \%$ and $17 \%$ of the total in two discussions, respectively. An average message length was approximately 6 lines

Table 6. Overview of two discussions in Class D

\begin{tabular}{|c|c|c|c|c|}
\hline Topic & $\begin{array}{l}\text { Network } \\
\text { size }\end{array}$ & Density & $\begin{array}{l}\text { Instructor's } \\
\text { message }\end{array}$ & $\begin{array}{l}\text { Average } \\
\text { message } \\
\text { line length }\end{array}$ \\
\hline $\begin{array}{l}\text { Pro-life and } \\
\text { Pro-choice } \\
\text { (Week 3) }\end{array}$ & 15 & $\begin{array}{l}36 \%[2 \times 38 / 15 \times \\
(15-1)] \\
38 \text { messages total }\end{array}$ & $\begin{array}{l}29 \% \\
\text { (11 messages) }\end{array}$ & $\begin{array}{l}6(27 \text { words/line }) \\
162 \text { words }\end{array}$ \\
\hline $\begin{array}{l}\text { AIDS disease } \\
(\text { Week } 8)\end{array}$ & 17 & $\begin{array}{l}40 \%[2 \times 54 / 17 \times \\
(17-1)] \\
(54 \text { messages total })\end{array}$ & $\begin{array}{l}17 \% \\
(9 \text { messages })\end{array}$ & $\begin{array}{l}4.8(27 \text { words/line }) \\
130 \text { words }\end{array}$ \\
\hline
\end{tabular}


and 4.8 lines, respectively (see Table 6). The density is 0.36 for the first week and 0.40 for the second week. This course is referred to as Class D in this study.

This online discussion enjoyed moderate instructor participation and interaction with students. Students in this class discussion interacted more with peers and the instructor than those in previous discussions.

Interaction viewed through the lens of network size, centrality, and density

The network size for the four discussions (Classes A-D) was relatively small, ranging from 8 to 18 , but the size was manageable and sufficient for a constructive dialogue. The small network size, indicating relatively fewer links among members of the network, does not affect the ways members interact. Although the network size may influence the network density (Ridley \& Avery, 1979), it is not clear whether the size will affect types of interaction in a network.

Centrality examined here was not relative, but absolute. It is calculated simply in terms of the number of points to which a particular point is adjacent, ignoring any indirect connections it may have. The following figures (Figures 1-4) illustrate interaction and centrality in social networks of four online discussions.

(a)
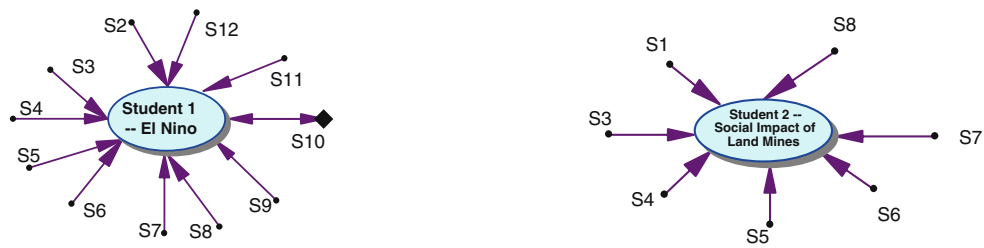

$\mathrm{S}=$ Student $\quad$ others $=$ Other Students

(b)

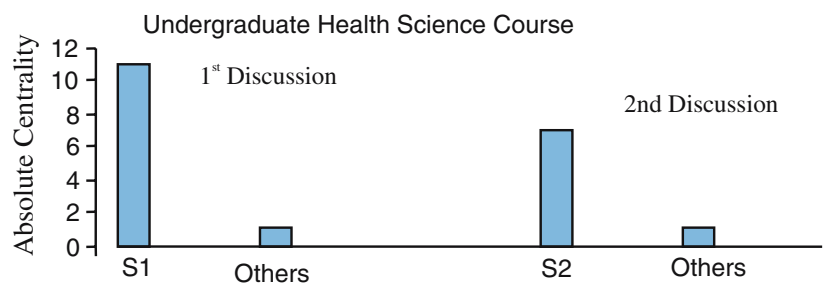

Figure 1. (a) Network interaction in Class A and (b) Centrality in two discussions of undergraduate health science course - Class A. 
(a)
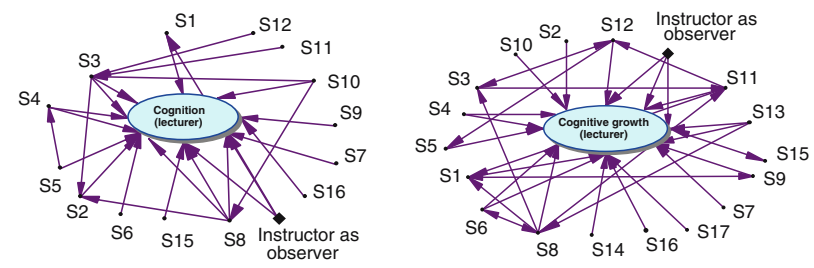

Inst $=$ Instructor

$\mathrm{S}=$ Student

others $=$ Other Students

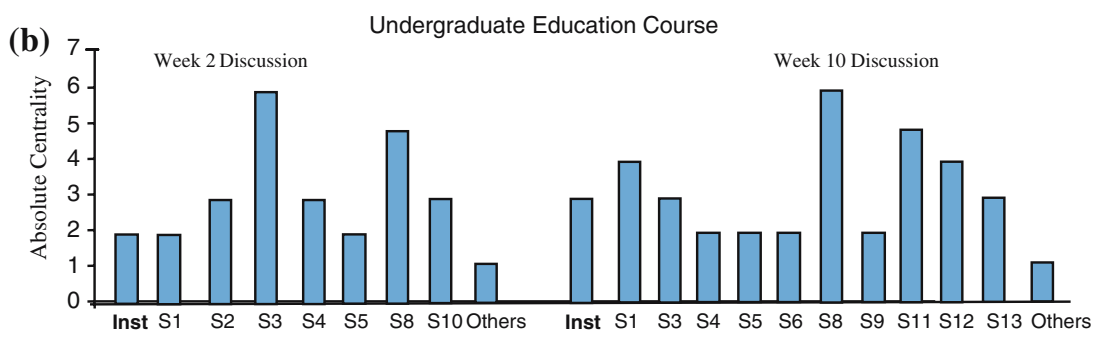

Figure 2. (a) Network interaction in Class B and (b) Centrality in two discussions of undergraduate education course - Class B.
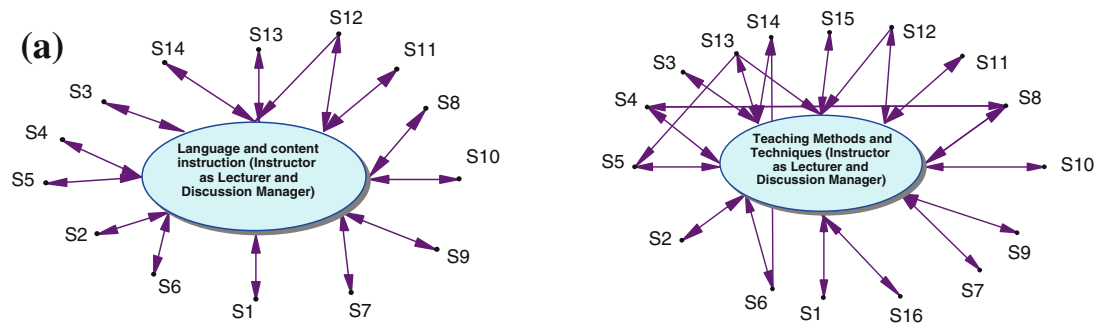

$\mathrm{S}=$ Student $\quad$ Others $=$ Other Students

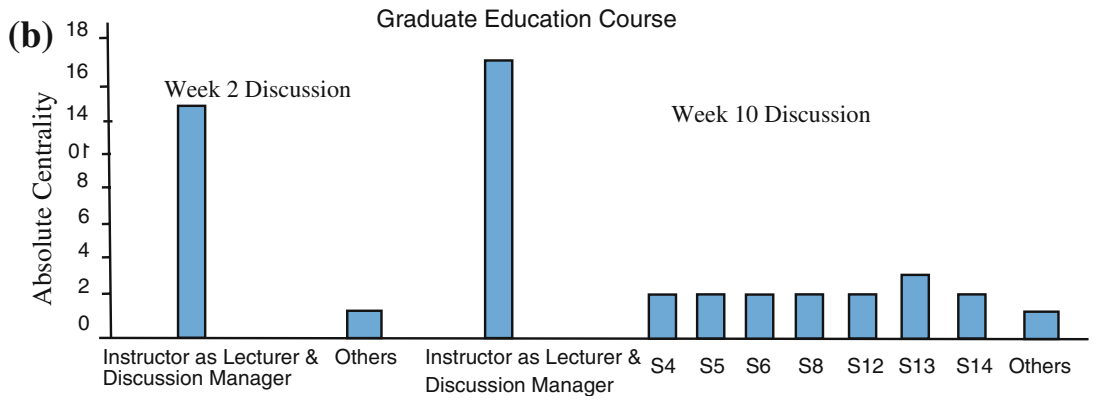

Figure 3. (a) Network interaction in Class $\mathrm{C}$ and (b) Centrality in two discussions of graduate education course - Class $\mathrm{C}$. 


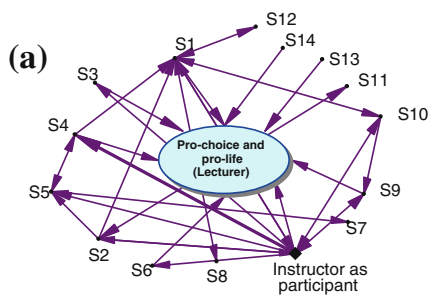

$\mathrm{S}=$ Student $\quad$ Others $=$ Other Students
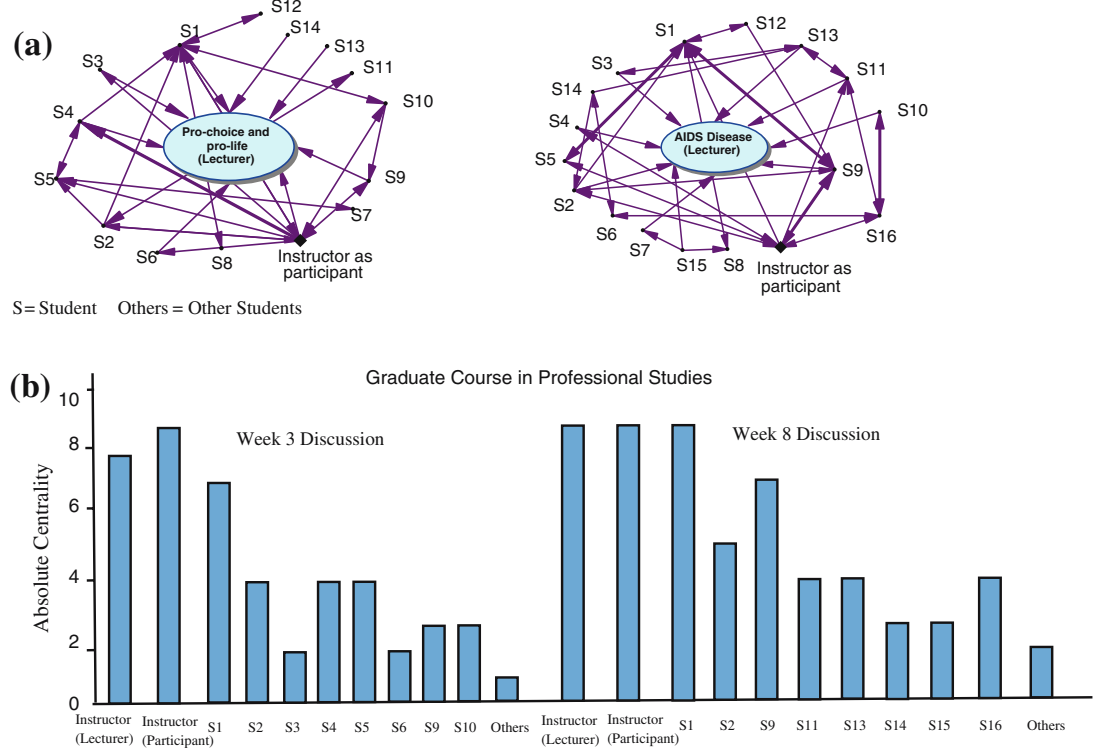

Figure 4. (a) Network interaction in Class D and (b) Centrality in two discussions of graduate course in professional studies - Class D.

The discussion in Class A formed a star type of network interaction, with one person either a student or an instructor connecting to other members in the network (see Figure 1a). A bi-directional connection is seen between Student 10 and Student 1, who responded directly to Student 10. For both discussions in Class A, responses went to the person who held a central position in the communication network and through whom the remaining students were connected. Student 1, who initiated the topic "El Nino," enjoyed a centrality of 11, whereas Student 2, who posted the topic "Social Impact of Land Mines," had a centrality of 8 . The absolute centrality was 1 for all other students (see Figure 1b).

The instructor in the undergraduate education course (Class B) posted weekly questions, and occasionally participated in the discussion. A few students interacted with one another during the discussion (see Figure 2a). For example, Student 3 responded to the instructor's question twice and interacted with 4 other students during the first week discussion. Student 11 interacted with 4 other group members in the second week. About half of the students had an absolute centrality greater than 2. An interconnected web type of interaction was visible in this online discussion (see Figure 2b). 
The instructor in the graduate education class (Class C) played dual roles: lecturer and discussion manager, posting reflective questions and managing the discussion by responding directly to each student. The instructor held a central position in the network and controlled the online discussion. The bi-directional arrows indicate that students responded to the instructor's question and received comments from the instructor (see Figure 3a). A few students responded to the instructor twice. Students did not interact with one another in the first discussion, but 6 students interacted with each other in the second discussion. Interaction in this class discussion was star type rather than interconnected web type. The absolute centrality was 1 for most students (see Figure 3b).

The instructor in the graduate professional studies course (Class D) likewise played dual roles: lecturer and discussion participant. The instructor posted weekly questions and participated in the discussion, but did not hold one central point nor control the discussion. In the network, there were multiple central points held by students. The thick lines between Student 4 and the instructor (as participant) in Week 3 and also among Student 1, Student 5, and Student 9 in Week 8 indicate multiple exchanges (see Figure $4 a$ ). The instructor, as a lecturer, received responses from students and, as a participant, interacted with 8 students during the discussion on Pro-choice and Pro-life issues. Student 1 interacted with 6 others in the discussion. Interaction among students in discussions was intertwined. Again, the absolute centrality was greater than 2 for most students in the first week and for all students in the second discussion (see Figure 4b).

\section{Density}

Density refers to the completeness of a network and the extent to which all possible relations are actually present (Scott, 2000). The density calculation is based on Berkowitz's formula (1982, p. 45).

Density $(D)=2 a / n(n-1)$, where $a=$ the actual number of interactions and $n=$ the number of participants in the network (Fahy et al., 2001; Scott, 2000).

The network density in the above discussions ranged from 0.20 to 0.40 . The density for weekly discussions in a particular class remained consistent. The low density once again showed the absence of relationship and interaction among members of the social network. The density in Class D is up to 0.36 and 0.40 , respectively. As shown in the Network Interaction in Class D (Figure 4a), more connections existed among members of the network. 


\section{Cognitive engagement}

The analyses reveal varied levels of cognitive engagement in four discussions (Classes A-D). The majority of students in Class A responded to discussion topics by providing factual information. Sixty-five percent of messages in the "El Nino" discussion belonged to Statement Type I (see Table 7). Twenty-eight percent messages raised questions that were horizontal in direction with no direct answers. Only 7\% messages offered explanations. For the discussion on "Social Impact of Land Mines," half of the messages were Statement Type I (responding), which responded directly to previous messages, $42 \%$ were Statement Type II (informative), and only $8 \%$ belonged to Statement Type III that gave explanations. No messages in Class A discussions were analytical, evaluative, or reflective.

The student cognitive engagement in Class B discussions was similar. Of the total number of messages in the first week, Statement Type I accounted for $76 \%$. In the second week, cognitive engagement involved four different types: Statement Type I (40\%), Question Type I (15\%), Statement Type II (15\%), and Statement Type III (30\%). However, discussion messages in Classes $\mathrm{C}$ and $\mathrm{D}$ showed varied

Table 7. Discussions messages in Classes A-D

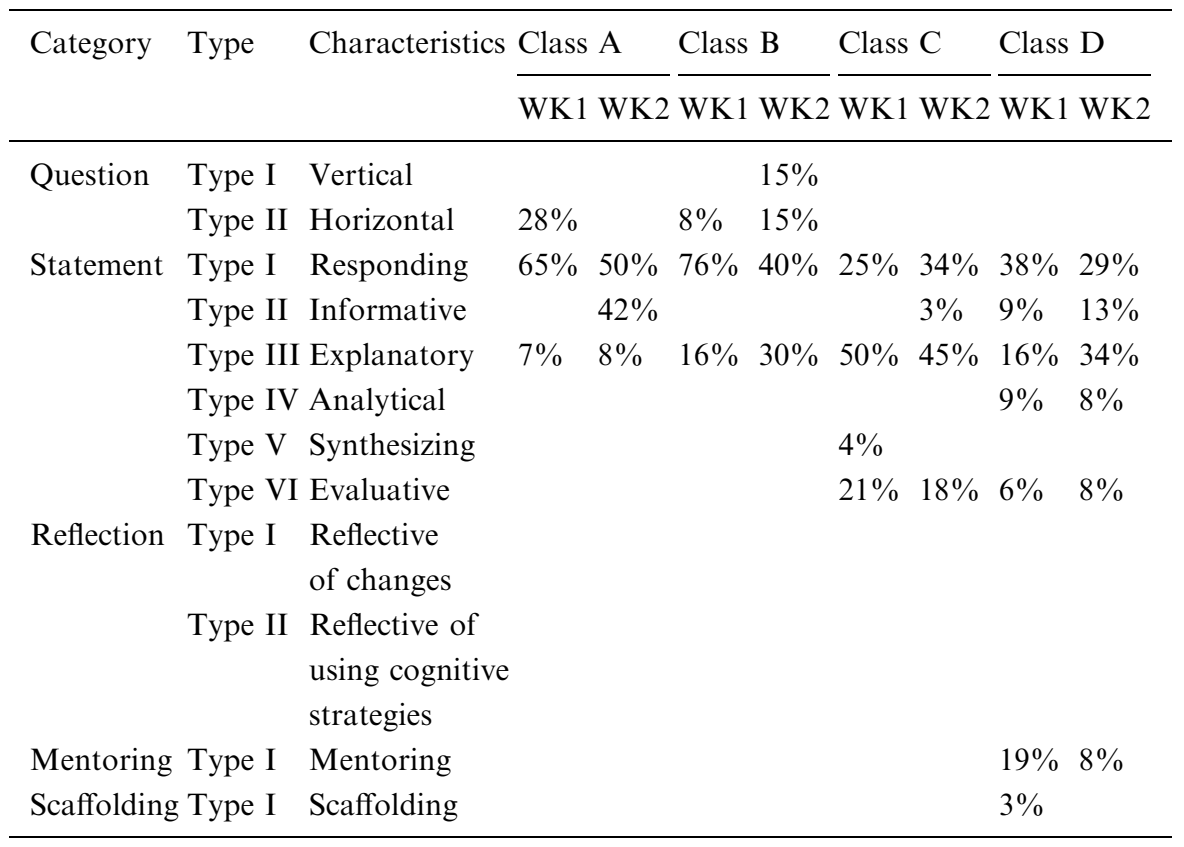

The percent in the table is all rounded to a whole point. $\mathrm{WK}=$ week 
levels of cognitive engagement, including mentoring and scaffolding. There was a large number of evaluative messages $(21 \%$ for the first week and $18 \%$ for the second week) in Class $\mathrm{C}$ because the instructor read students' messages and responded with evaluative comments to each student, but there were no mentoring and scaffolding messages since the instructor was just looking for specifics in students' responses and did not demonstrate or model how to construct understanding and knowledge. In contrast, Class D discussions included messages that offered suggestions and guidance $(8 \%$ Mentoring Type I and 8\% Statement Type VI). Thirty-four percent of messages explained personal opinions on related readings and one third of messages $(29 \%)$ responded to peers. The instructor participated as a peer as well as a mentor in the discussion, offering personal opinions, facts, and also pieces of encouragement, guidance, and suggestions.

Finally, the analyses showed that students in Classes C and D demonstrated a higher level of cognitive engagement during discussions, whereas students in Classes A and B engaged in the discussion at a low cognitive level despite the similarity and difference in the interaction type (see Table 8). Since discussion participation was part of the course grade, the number of students who chose to remain silent for a specific discussion session was small (see Table 1). Those students who "sat out of a discussion" or "lurked" in the study can loosely be labeled as "lurkers", but mandatory and graded online discussions made it hard for students to remain inactive or lurk in discussions for a prolonged period of time as they may in any public forums. Lurkers and lurking are part of an online group and without insight into lurkers and lurking, our understanding of online groups is incomplete (Nonnecke \& Preece, 2003). Although students here demonstrated behaviors of lurkers, but reasons for lurking may be drastically different from those in a public forum. We need to study and understand reasons for "lurking" in a mandatory class discussion just

Table 8. Summary of cognitive engagement and interaction type in discussions Classes A-D

Interaction Type

Start

Interconnected Web

Cognitive engagement

Low

Class A

Class B

High

Class C

Class D 
as we need to know why students choose to skip lectures in a face-toface class. This would be a research question for follow-up studies. For this study, I will view student participation in the four discussions as normal student behaviors. Their levels of cognitive engagement can also be seen as representing student engagement in online discussions, but they, by no means, can be representative of student cognitive engagement and learning in the course.

\section{Discussion}

\section{Types of interaction in four asynchronous online discussions}

The analyses showed two types of interaction in the asynchronous online discussions: star and interconnected web (see Table 7). The star type of interaction was mostly centralized, either uni-directional or bidirectional as demonstrated in Classes A and C. One person, whether a student or an instructor, who proposed discussion topics or questions took the point of centrality, connecting members in the network, while others remained isolated. The star type interaction, characterized by a single point of centrality, also has low network density, which implies no or little interpersonal relations among other members of the network. In this loosely connected network, mutual assistance in accomplishing learning tasks will be less consistent, more fragmented, or even rare.

The interconnected web type of interaction is characterized by multiple points of centrality. This type of interaction was apparent in Classes B and D, where more members of the network had a centrality greater than 1 or 2 . For instance, every member in Class D interacted with two or more other members during the discussion. With this type of interaction, students were more likely to exchange, elaborate on, and challenge each other's ideas. The action of sharing, exchanging, and defending one's ideas helped students remember and understand the learning material.

In a network with star type of interaction, the power resides in a central point or person, who has the potential to control the agenda and direction of the discussion. The online discussion and instruction, including learning agendas, can be teacher-controlled and centered. This proves to be contrary to the inferences made from other studies claiming that online instruction, in turning over control of instructional time and space to the student, altered the disciplinary power of 
classrooms and teacher-controlled learning agendas (Jeris, 2002). In the interconnected web type of interaction, however, multiple people can direct or lead a discussion. The instructor sets the learning goal, but the instructor and students together can negotiate the process of reaching the goal. From this perspective, the interconnected web type seems more conducive for collaboration and knowledge construction.

The findings show that it is unrealistic to assume that online discussion will engage and improve interaction between students and instructors and among students themselves under any circumstances. The study also confirms that interaction does not simply occur due to the discussion online, but it must be intentionally integrated into the discussion and course (Berge, 1999; King \& Doerfert, 1996), and nurtured by the instructor and students. The findings further reveal that an instructor's course/discussion design rather than the online environment (i.e., easy of posting messages and replying to peers' message) that may regulate students' posting behaviors. Other factors that contributed to the types of interaction are found to be instructors' role in the discussion, facilitation, and discussion questions.

\section{Levels of cognitive engagement in the asynchronous online discussions}

The study found that levels of cognitive engagement in four discussions ranged from low to high. The discussion messages in Classes $\mathrm{C}$ and $\mathrm{D}$ providing explanation, analysis, and evaluation showed higher levels of cognitive engagement. The activities of analysis and synthesis that are based on information and facts are evident in the transcripts of Class D discussions. Deeper levels of information processing are associated with elaborating concepts (Gagne, 1985), and debating or negotiating meaning, which is more likely to lead to understanding.

The discussion messages in Classes $\mathrm{A}$ and $\mathrm{B}$, providing or retrieving factual information, demonstrated predominantly low levels of cognitive engagement and surface level of information processing. The lower level of cognitive engagement found in this study resembles findings from the previous research (Garrison et al., 2001; Kanuka \& Anderson, 1998), which found that most of the conversation in online discussions was of a sharing and comparing nature. Dissonance and inconsistency in the discussion were not actively explored. Little testing of evidence against experience or the literature was expressed, and participants rarely stated the relevance or application of new knowledge that was created (Kanuka \& Anderson, 1998). Online conferencing provides an interactive environment that creates effective means 
for implementing constructive strategies that would be difficult to accomplish in other environments (Driscoll, 1994). However, as shown in the study, the action of social sharing and knowledge construction did not come naturally because of the online discussion or the online learning environment, but because of the careful planning of learning activities and facilitation during the learning process. In addition to learning design and facilitation, it is not clear whether and how social presence (Rourke, et al., 2001), may influence cognitive presence in an online discussion.

Online discussion can engage students in either lower or higher level of cognitive engagement. When lower in cognitive engagement, students may not gain or learn much from the discussion, but that certainly does not apply to student learning in the course since online discussions capture only part of student learning activities in the course. Of course, more studies are needed to verify whether levels of cognitive engagement directly relate to student learning in a course.

\section{Relationship between types of interaction and cognitive engagement}

The study results showed no direct relationship between levels of cognitive engagement and types of interaction in the asynchronous online discussions. The interaction type in Classes $\mathrm{A}$ and $\mathrm{C}$ was the same, but levels of cognitive engagement were different; low level of cognitive engagement in Class A, but high in Class C. Levels of cognitive engagement in Classes B and D were again quite different, low in Class $\mathrm{B}$, but high in Class $\mathrm{D}$, although the interaction type was similar.

We may, however, infer from the study that cognitive engagement in online discussions might be indirectly linked to instructors' questions and roles they played. The Class $\mathrm{B}$ instructor raised questions about cognition and children's cognitive growth. These questions could generate higher levels of cognitive engagement. Students in this class posted merely definitions from the textbook or dictionaries, and rarely expressions or reflections of their own understanding. Although definitions from textbooks or dictionaries were legitimate answers, students could have been challenged. The instructor posted questions and expressed dissatisfaction with the quality of student messages, but did not challenge them or guide them to a deeper level of processing and understanding. Without the help of a mentor who has a higher level of understanding and who can scaffold student learning, an individual may find difficulty to achieve independent competency in learning (Gredler, 1997). Even though the Class B instructor kept encouraging 
students to ask questions and think deeply, students still felt at loss as to where and what to question. Lack of guidance and scaffolding may possibly cause the lower level of cognitive engagement in the discussion.

Students' prior knowledge of the subject might also impact their levels of cognitive engagement, which can be somewhat misleading. Students with higher level of prior knowledge may post synthesis messages with little effort made in writing them, but students with lower level of prior knowledge may post similar messages with huge effort made in summarizing and synthesizing discussion points. Academic maturity might be another factor that influence the level of cognitive engagement. As occurred in this study, graduate students in Classes $\mathrm{C}$ and D engaged deeply in the discussion than those in Classes A and B. However, it is not clear whether and how the level of cognitive engagement in discussions relates to students' academic maturity. Similarly, it is not clear how prior knowledge may impact student cognitive engagement in online discussions.

The instructor's presence in an online discussion revealed to be another possible factor influencing types of interaction and levels of cognitive engagement. When an instructor is absent from the discussion or participates in the discussion marginally (e.g., Classes A and $\mathrm{B}$ ), the discussion messages tend to be informative and explanatory in nature. On the other hand, when the instructor reads and evaluates every single message in the discussion, he or she may stifle the discussion. Well-balanced messages from the instructor that spread throughout the continuum of levels of engagement may lead students to a higher level of cognitive engagement during a discussion. The instructor's effort in and contribution to a discussion, thus, may correlate positively, but may also negatively sometimes, with student cognitive engagement in the discussion. As $\mathrm{Ng}$ and Murphy explain, learners' involvement does not seem to rely on the tutors' input ( $\mathrm{Ng} \&$ Murphy, 2005). Gilbert and Dabbagh's research revealed similar findings that certain structuredness and evaluation criteria positively influenced meaningful discourse in asynchronous online discussions, whereas others may have had a negative impact (Gilbert \& Dabbagh, 2005).

\section{Effects of interaction and cognitive engagement on learning and teaching}

Learning and teaching are active, accumulative, and goal oriented, but that does not mean that learning and teaching have be active and 
accumulative at all time. In reality, active learning periods and passive ones take turns, especially for learning intellectual skills. Learners could be extremely active, highly motivated, and reflective at one time, but less active and reflective at another ( $\mathrm{Zhu}, 1998)$. This applies to both learning face-to-face and online. In a face-to-face learning environment, we find that some students are quite vocal and active in class discussions, but others are more reticent. In an online discussion, students may read messages without contributing to one discussion session and students may contribute multiple messages, both of which seems normal in the learning process. That may explain why students chose to remain silent for one or two discussion sessions when discussion participation was mandatory in this study. In gathering and processing information and constructing knowledge, star and interconnected web types of interaction are both essential for effective learning. Learners in the star type of interaction may passively or actively receive or seek information, while learners in the interconnected web type of interaction may engage in seeking information, but also actively process information. Both types of interaction help learners achieve goals in different stages of the learning process.

However, when the interaction type mismatches the discussion goal, students are less likely to benefit and learn much from the discussion. The discussion in Class A, for example, was designed for information exchange. Although students did not interact much with one another during the discussion and most messages were Statement Type I and Statement Type III, students generated and exchanged an enormous amount of information (a total of 271 messages). The amount of messages exchanged is impossible for a 1.5-hour face-toface discussion session. In a sense, the online discussion in Class A served as an effective method for supplementary information exchange. If the discussion goal switched from information exchange to knowledge construction, the discussion in Class A might not be effective in facilitating students to reach the goal.

Although possible for deeper cognitive engagement and constructivist learning, the online learning environment, such as a discussion forum, does not guarantee student learning if the instructor and students do not take the full advantage of what an online discussion forum can offer for them. Students in Class $\mathrm{C}$ were quite disconnected or isolated. The online discussion served as a storage space for an electronic collection of individual reflection papers and the instructor's feedback, rather than a discussion 
forum, where exchanges of ideas and opinions occur. In Class D, both the instructor and students benefited from taking the full advantage of an online discussion forum and using it as a tool as well as an environment for learning and negotiating understanding. Students exchanged thoughts and ideas on discussion topics as well as negotiated, debated, and defended their own positions on various issues. One of the discussion goals was to learn how to express one's own opinions and discuss them with people of opposite opinions in a respectful and civilized manner, rather than to seek a right answer. The instructor carefully planned the discussion with detailed instructions and well-crafted questions and used the online discussion to help students achieve this goal. The assumption that any online interaction is educationally valuable does not prove to be true in the study.

Online discussions with interaction among students and the instructor facilitate information sharing, knowledge construction, and achieving other learning goals. However, it is clear that while interaction can benefit learning and teaching, it needs to be nurtured carefully in accordance with course goals and learning objectives. While goals need to be defined, techniques and methods for nurturing interaction also require careful consideration and identification in order to promote the desired type of interaction. It is unrealistic to view any type of interaction as beneficial to any instruction and to assume that interaction occurs naturally. This proves to be quite consistent with the hypothesis verified in another study (HowellRichardson \& Mellar, 1996), in which the author reported that even relatively minor differences in course design and in moderator's behavior can influence the patterns of interaction of online conferencing. Of course, this does not imply that informal learning and interaction in other online communities, such as chat and blog, need to be structured and goal-oriented since students learn both in and outside of the course.

Types of interaction in an online discussion can be different; so can levels of cognitive engagement be; both are affected by multiple factors. Because of multiple and interactive factors, it is impossible for one to suggest or prescribe guidelines for online instruction and discussion, but it is imperative for us to realize that multiple factors influence each other, which in turn may effect student learning. While recognizing multiple interacting factors, instructors can manipulate factors to promote student learning; researchers can examine and explore factors to advance research in $\mathrm{CMC}$. 


\section{Implications for learning, teaching, and research}

Learning and knowledge construction require students to be in an environment that they can interact with one another and engage cognitively at all levels. As instructors, we should be very clear about learning goals and outcomes, and design appropriate activities that engage students in learning and useful strategies that assist them in moving between levels of cognitive engagement. While an online discussion lends itself well for interaction, instructors should understand characteristics of an online discussion, utilize facilitating factors such as presence, role, and discussion design and questions to foster interaction and levels of cognitive engagement, which, in turn, can impact student learning and performance. It is unrealistic to simply plunge students into an online discussion and expect that learning occur naturally without much of facilitation or consideration of the learning task, outcome, and environment.

As noted, many factors or variables may influence interaction and cognitive engagement in an online discussion and student learning in an online environment. The variables may include the instructor's presence, role, and expectations, which may be clarified in terms of discussion goals, and facilitation, and discussion questions, class size, delivery format, percentage of final course grade, gender, and student academic maturity. Although I collected information on courses and students, the data were far from sufficient to explore and explain the complex relations among variables. In addition, student intrinsic motivation and prior knowledge of and interest in the topic may also influence levels of cognitive engagement and interaction with peers during the discussion. Students with a higher level of prior knowledge of the subject may feel bored, while students with limited prior knowledge may find interesting in contributing to the discussion. As students' cognitive engagement in online discussion is one indicator of student cognitive engagement and learning in the course, it is important to explore the correlation among measures of cognitive engagement to understand how each student engages and learns in an online course. All these are essential for us to explore and understand, the role of online discussion, online instruction, and student learning, but they are well beyond the scope of the present study.

This preliminary study, examining types of interaction and cognitive engagement in the online discussion, provides valuable information on how students interact and engage in an online forum in 
social science courses. The results showed no causal relationship between interaction types and levels of cognitive engagement, but the findings cannot be generalized because the small number of courses and students from limited academic units in the present study. The study revealed multiple factors that interact and influence both interaction and cognitive engagement in online discussions. Future studies, recruiting a large number of students from a variety of disciplines, such as science, technology, and engineering, should be conducted to confirm this hypothesis and to further explore the complex relations among these variables so that we can understand their impacts on the online discussion, instruction, and learning in general. In addition to transcript analysis, qualitative data from student and instructor interviews will be necessary to enrich our understanding of multiple factors and their effects on learning. Content analysis, as a method for measuring cognitive engagement, needs to be further examined, especially in its validity and reliability. Methodology of combining network structural and content analyses to analyze interaction and cognitive engagement in discussions can also be modified to further improve the study's objectivity and reliability.

\section{Conclusions}

As online discussion becomes an integral part of face-to-face and online courses, instructors need to be aware of the decision they make and the consequences it may bring to learning and instruction. Although interaction type and cognitive engagement do not seem to correlate in the asynchronous online discussion, they might result from the goals that an instructor sets for the discussion, the roles the instructor assumes in the discussion, facilitation, and many other involving variables. Each type of interaction and level of cognitive engagement plays a unique role in the teaching and learning process. For an online class discussion to be effective, the discussion activity, as any other learning activities, has to be closely connected with student learning goals and course objectives. For students to learn from the online discussion, the instructor should understand and distinguish variables in the online learning environment so that they can foster student learning by working with those variables that may have great impact on learning and performance. 


\section{References}

Berelson, B. (1952). Content analysis in communication research. Illinois: Free Press. Berkowitz, S.D. (1982). An introduction to structural analysis. Toronto: Butterworths. Berge, Z.L. (1999). Interaction in post-secondary Web-based learning. Educational Technology 39(1): 5-11.

Berge, Z.L. \& Collins, M. eds. (1995). Computer mediated communication and the online classroom. Vol. 1: Overview and perspectives. Cresskill: Hampton Press, Inc.

Bloom, B.S. (1956). Taxonomy of educational objectives; The classification of educational goals. New York: Longmans.

Corno, L. \& Mandinach, E.B. (1983). The role of cognitive engagement in classroom learning and motivation. Educational Psychologist 18(2): 88-108.

Driscoll, M.P. (1994). Psychology of learning for instruction. Boston: Allyn and Bacon.

Fahy, P.J., Crawford, G. \& Ally, M. (2001) Patterns of interaction in a computer conference transcript. International Review of Open and Distance Learning, 2(1). Retrieved on January 18, 2004 at http://www.irrodl.org/content/v2.1/fahy.html.

Gagne, R. (1985). The conditions of learning. New York: Holt, Rinehart \& Winston.

Garrison, D.R., Anderson, T. \& Archer, W. (2001). Critical thinking and computer conferencing: A model and tool to assess cognitive presence. American Journal of Distance Education 15(1): 7-23.

Gilbert, P. \& Dabbagh, N. (2005). How to structure online discussions for meaningful discourse: A case study. British Journal of Educational Technology 36(1): 5-18.

Gredler, M.E. (1997). Learning and instruction: Theory into practice. Upper Saddle River, NJ: Prentice-Hall.

Gunawardena, L., Lowe, C. \& Anderson, T. (1997). Interaction analysis of a global online debate and the development of a constructivist interaction analysis model for computer conferencing. Journal of Educational Computing Research 17(4): 395-429.

Hara, N., Bonk, C.J. \& Angeli, C. (2000). Content analyses of on-line discussion in an applied educational psychology course. Instructional Science 28(2): 115-152.

Harasim, L. (1990). Online education: An environment for collaboration and intellectual amplification. In L. Harasim, ed, Online education: Perspectives on a new environment, pp. 39-66. Praeger Publishers: New York.

Heckman, R. \& Annabi, H. (2004) A content analytic comparison of learning processes in online and face-to-face case study discussions. Retrieved June 2005 from http:/ jcmc.indiana.edu/vol10/issue2/heckman.html.

Henri, F. (1992). Computer conferencing and content analysis. In A.R. Kaye, ed, Collaborative learning through computer conferencing: The Najaden papers, pp. 117136. Springer-Verlag: London.

Howell-Richardson, C. \& Mellar, H. (1996). A methodology for the analysis of patterns of participation within computer mediated communication courses. Instructional Science 24(1): 47-69.

Jeong, A. (2005) Methods and tools for the computational analysis of group interaction and argumentation in asynchronous online discussions. Paper presented at the 2005 Technology and Learning Symposium, New York, NY.

Jeris, L. (2002). Comparison of power relations within electronic and face-to-face classroom discussions: A case study. Australian Journal of Adult Learning 42(3): $300-311$. 
Jonassen, D., Davidson, M., Collins, M., Campbell, J. \& Haag, B.B. (1995). Constructivism and computer-mediated communication in distance education. The American Journal of Distance Education 9(2): 7-26.

Kanuka, H. \& Anderson, T. (1998) Online social interchange, discord, and knowledge construction. Journal of Distance Education 13(1). Retrieved June 2004 from http:// cade.athabascau.ca/vol13.1/kanuka.html.

King, J.C. \& Doerfert, D.L. (1996) Interaction in the distance education setting. Retrieved on January 2004 from http://www.ssu.missouri.edu/ssu/AgEd/NAERM/ s-e-4.htm.

Merriam-Webster's Collegiate Dictionary (1997). 11th edition. Springfield, MA: Merriam-Webster Inc.

Moore, M. (1993). Theory of transactional distance. In D. Keegan, eds, Theoretical principles of distance education, pp. 22-38. Routledge: London and New York.

Ng, K.C. \& Murphy, D. (2005). Evaluating interactivity and learning in computer conferencing using content analysis techniques. Distance Education 26(1): 89-109.

Nonnecke, B. \& Preece, J. (2003). Silent participants: Getting to know lurkers better. In C. Leug and D. Fisher, eds, From usenet to CoWebs: Interacting with social information spaces, Springer-Verlag: Amsterdam, Holland.

Paiget, J. (1970). The science of education and the psychology of the child. NY: Grossman.

Riedl, R. (1989). Patterns in computer-mediated discussions. In R. Mason and A. Kaye, eds, Mindweave: Communication, computers, and distance education, pp. 215-220. Pergamon Press: Oxford.

Rogoff, B. (1990). Social interaction as apprenticeship in thinking: Guided participation in spatial planning. In L. Resnick et al., eds, Perspectives on socially shared cognition, pp. 349-365. American Psychology Association: Washington, D. C.

Rohfeld, R.W. \& Hiemstra, R. (1995). Moderating discussions in the electronic classroom. In Z. Berge and M. Collins, eds, Computer mediated communication and the online classroom Volume 3: Distance learning, pp. 91-104. Hampton Press: Cresskill, NJ.

Rourke, L., Anderson, T., Garrison, D.R. \& Archer, W. (2001) Assessing social presence in asynchronous, text-based computer conferencing. Journal of Distance Education. Retrieved in February 2006 from http://cade.icaap.org/vol14.2/rourke_et_al.html.

Ridley, C. \& Avery, A. (1979). Social network influence on the dyadic relationship. In R. Burgess and T. Huston, eds, Social exchange in developing relationships, pp. 223-246. Academic Press: New York.

Rytina, S. (1982). Structural constraints on intergroup contact. In P. Marsden and N. Lin, eds, Social structure and network analysis, pp. 81-100. Sage Publications: Beverly Hills.

Scott, J. (2000). Social network analysis: A handbook. London: Sage Publications.

Stoney, C. \& Oliver, R. (1999) Can higher order thinking and cognitive engagement be enhanced with multimedia? Interactive Multimedia Electronic Journal of ComputerEnhanced Learning. Retrieved in February 2006 from http://imej.wfu.edu/articles/ 1999/2/07/index.asp.

Vygotsky, L.S. (1978). Mind in society: The development of higher psychological processes. Cambridge, MA: Harvard University Press.

Wellman, B. (2001) Computer networks as social networks. Retrieved January 2005 from http://www.chass.utoronto.ca/ wellman/publications/science/science.pdf. 
Wellman, B. \& Hiltz, S. (2004) Sociological Rob: How Rob Kling brought computing and sociology together. Information Society 20(2): 91-95.

Zhang, K. \& Carr-Chellman, A. (2001) Peer online discourse analysis. In Annual proceedings of selected research and development [and] practice papers. Presented at the 24th National Convention of the Association for Educational Communications and Technology, Atlanta, GA, November 8-12, 2001.

Zhu, E. (1998). Learning and mentoring: Electronic discussion in a distance learning course. In C. Bonk and K. King, eds, Electronic collaborators: Learner-centered technologies for literacy, apprenticeship, and discourse, pp. 233-259. Lawrence Erlbaum Associates: New Jersey. 